\title{
KAJIAN DESAIN KAPAL PURSE SEINETRADISIONAL DI KABUPATEN PINRANG (STUDY KASUS KM. CAHAYA ARAFAH)
}

\author{
Design Studies Traditional Purse Seiner In Pinrang (Case Study Km. Cahaya Arafah) \\ Oleh: \\ Muh. Arkam Azis ${ }^{1 *}$, Budhi Hascaryo Iskandar², Yopi Novita² \\ ${ }^{1}$ Mahasiswa Program Pasca Sarjana Departemen PSP FPIK IPB \\ ${ }^{2}$ Departemen PSP FPIK IPB \\ *Korespondensi: arkam.pru@gmail.com
}

\begin{abstract}
ABSTRAK
Kapal perikanan merupakan kendaraan utama nelayan untuk menuju kefishing ground dan mengangkut alat tangkap khususnya purse seine. Di Kabupaten Pinrang kapal dibangun secara tradisional tanpa perhitungan naval arsitektur. Dimana alat tangkap purse seine di Kabupaten Pinrang mempunyai ukuran panjang jaring 220 depah dengan kedalaman jaring $36 \mathrm{~m}$. Purse seine juga merupakan alat tangkap yang menangkap ikan bersifat schooling fish, sehingga harus memiliki kapasitas besar dan desain yang sesuai dengan alat tangkap yang dibawanya. Oleh karena itu penelitian ini mengkaji desain kapal purse seine di Kabupaten pinrang dengan menggunakan study kasus dan dianalisis dengan simulasi numerik sehingga mengahasilkan kapal di Kabupaten Pinrang memiliki model kasko yang berbentuk round bottom dan body yang ramping serta rasio dimensi kapal sudah sesuai dengan kapal-kapal (encircling) di Indonesia. Pada nilai koefisien bentuk hanya Cp dan Cw yang berada pada kisaran sehingga sesuai dengan tahanan gerak pada kapal encircling di Indonesia.
\end{abstract}

Kata kunci: kapal perikanan, purse seine, desain, dimensi

\section{ABSTRACT}

Fishing vessel are the main vehicle to get to the fishing ground and transporting the purse seine fishing tools. In Pinrang ship built with traditional without calculation of naval architecture. The purse seine fishing tools in Pinrang has a leght of nets 220 depah with a depth nets 35 meters. Purse seine also the fishing tools who fished the fish which scooling fish so it must have a large capacity and design in accordance with the fishing tools was carrying. This study reviewing the design of purse seine in Pinrang with studied case and analyzed by numeric simulation so the result, the ship in Pinrang has body models that shaped round bottom and slim body as well as the ratio of fishing vessel dimension are in accordance the other fishing vessel (encircling) in Indonesia, on the coefficient value of shape only $C_{p}$ and $C_{W}$ which is in the range so in accordance with the resistance motion on the encircling fishing vessel in Indonesia.

Keywords: fishing vessel, purse seine, design, dimension

\section{PENDAHULUAN}

\section{Latar Belakang}

Kabupaten Pinrang Sulawesi Selatan adalah salah satu Kabupaten andalan Provinsi Sulawesi Selatan di Bidang perikanan Khususnya Pada Perikanan Purse Seine, pada umunya produksi purse seine juga harus diimbangi dengan armada penangkapan yang digunakan yakni kapal purse seine.

Nelayan Purse seine di Kabupaten Pinrang merupakan nelayan tradisional yang masih menggunakan kapal-kapal yang berbahan dasar kayu yang dibangun oleh 
pengrajin kapal setempat. Kapal yang di buat di kabupaten Pinrang merupakan kapal tradisional yang dibangun tanpa adanya perhitungan-perhitungan modern atau Naval Arsitektur namun hanya menggunkan cara yang turun temurun serta menggunakan alat yang seadanya.

Kapal merupakan armada penangkapan yang digunakan nelayan untuk menuju ke fishing ground dan mengoprasikan alat tangkap khususnya purse seine namun kapal haruslah disesuaikan dengan alat tangkap yang dibawahnya serta lokasi penangkapan ikan. Keberhasilan suatu kapal penangkap ikan adalah apabila memeenuhi 3 (tiga) faktor yaitu laik laut, laik Operasi, dan laik simpan. Laik laut sangatlah berpengaruh terhadap performa kapal dilaut sehingga desain kapal harulah diperhatikan dan disesuaikan oleh kreteria kapal perikanan Indonesia.

Kapal Purse seine termasuk jenis kapal encircling dan merupakan kapal yang digunakan untuk membawa alat tangkap purse seine yang menangkap ikan yang bersifat schooling fish. Oleh karena itu kapal harus memiliki kapasitas dukung yang besar dan sebagai kapal yang membawa alat tangkap yang diperasikan dengan cara dilingkari maka kestabilan sangat penting. Menurut Fyson (1985) bahwa purse seine umumnya memilik hasil tangkapan dalam jumlah bnyak sehingga perlu dirancang agar memiliki kapasitas daya muat yang tinggi.
Berdasarkan pemaparan diatas maka dilakukan kajian mengenai desain bentuk kapal purse seine tradisional di kabupaten pinrang dikaitkan dengan teori-teori Standar kapal di Indonesia.

\section{Rumusan Masalah}

Pembagunan kapal secara tradisional yang mengadalkan ilmu secara turun temurun tanpa melakukan kaida-kaida naval arsitektur sehingga harus diketahui desain kapal yang dibuat secara tadisional, apakah sudah baik jika dilihat dari segi perhitungan naval arsitektur.

\section{Tujuan Penelitian}

Tujuan dari penelitian ini untuk mengatahui desain kapal purse seine yang dibangun secara tradisional pada Kabupaten Pinrang Sulawesi Selatan.

\section{METODE PENELITIAN}

Penelitian ini dilakukan pada bulan Juli - September 2016 di Kabupaten Pinrang Sulawesi Selatan dengan menggunakan metode studi kasus dan simulasi numerik dimana data kapal purse seine yang digunakan yaitu dengan mengukur (LOA, B, D dan LWL) dan akan diolah dengan bantuan aplikasi perkapalan yaitu untuk mendesain kapal, menggambar general arrangement, lines plan, dan parameter hidrostatis. Kapal purse seine yang menjadi sampel dapat dilihat pada Gambar 1 .

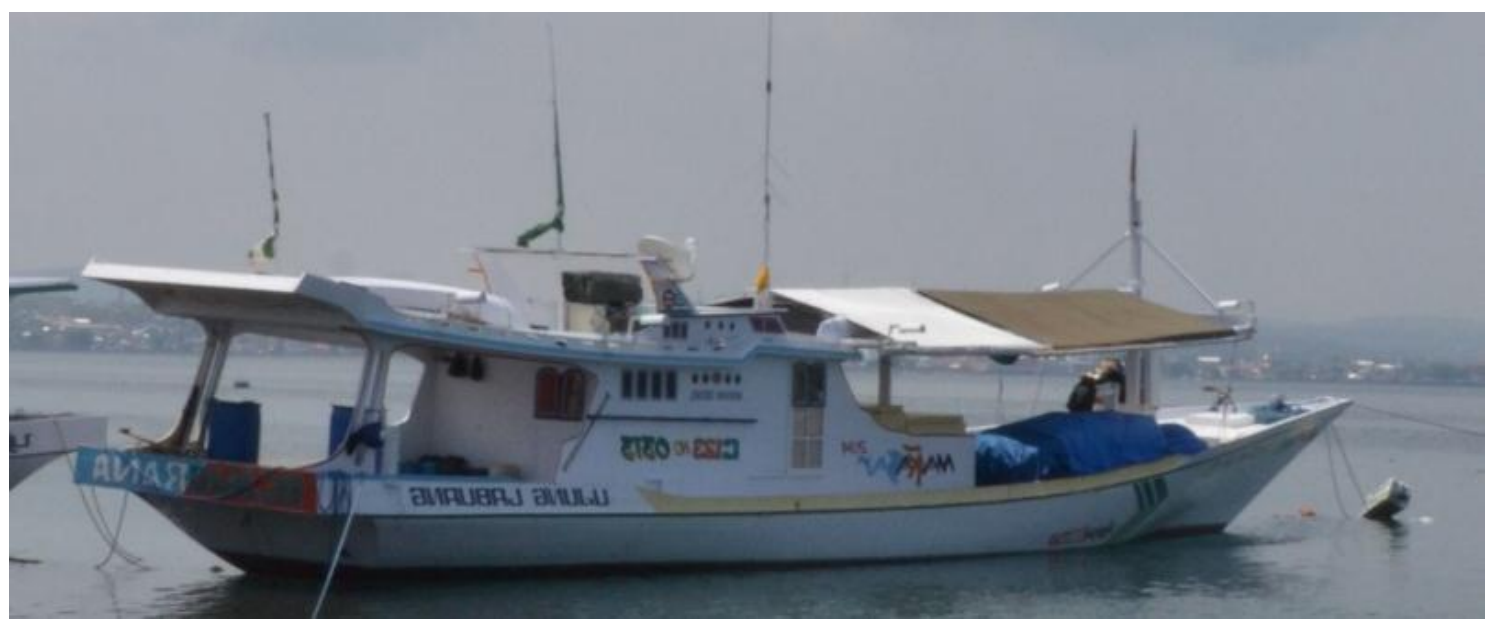

Gambar 1 Kapal Purse seine di Pinrang (KM. Cahaya arafah) 
Tabel 1 Ukuran Utama Kapal Sampel

\begin{tabular}{c|cc|c|c}
\hline \multirow{2}{*}{$\begin{array}{c}\text { KM. Cahaya } \\
\text { Arafah }\end{array}$} & LOA (M) & B (M) & D (M) & d (M) \\
\cline { 2 - 5 } & 20 & 4 & 1.30 & 1 \\
\hline
\end{tabular}

Analisis data yang digunakan dalam menyelesaikan penelitian ini dilakukan membandingkan ukuran utama (principal dimension) kapal purse seine sampel dengan teori yang mengatakan jika nilai L/B mengecil akan berpengaruh buruk terhadap kecepatan, nilai L/D membesar kekuatan panjang akan melemah, nilai B/D membesar stabilitas akan naik tetapi kemampuan mendorong akan memburuk. Perbandingan nilai yang baik untuk kapal di Indonesia diacuh dalam penelitian Iskandar dan Pujiati (1995), dan serta membandingkan dengan kapal purse seine di Jepang yang diacuh dalam tulisan Ayodhyoa (1972), kemudian untuk mengetahui bentuk desain kapal purse seine akan dilakukan analisis hasil dari gambar yaitu parameter hidrostatis.

\section{HASIL DAN PEMBAHASAN}

\section{Spesifikasi Teknis}

Dimensi utama kapal kapal purse seine di Kabupaten pinrang relative sama, hal itu dikarenakan galangan kapal tradisinal yang membangun kapal sama dan beberapa faktor modal serta ketersedian bahan yang ada di Kabupaten tersebut. Ukuran utama kapal purse seine sampel yaitu panjang (LOA), lebar (B), dalam (D), dan Sarat air (d) dapat di lihat pada tabel 1 berikut.

Dilihat pada tabel 1 ukuran utama kapal purse seine dengan LOA $20 \mathrm{M}$ membawa alat tangkap purse seine dengan ukuran panjang jaring 220 depah dengan kedalaman jaring 36 meter dan kapal digerakkan dengan mesin penggerak yang yang berkekuatan $125 \mathrm{HP}$ dengan merk mesin mistsubisi 6D15.

\section{Rasio Dimensi Utama}

Kapal perikanan merupakan kapal yang tidak memiliki alur pelayaran tetap dan desain dari kapal perikanan harulah disesuaikan dengan cara pengoprasian alat tangkap. Rasio dimensi utama digunakan untuk mengetahui karasteristik kapal perikanan dan mengidentifikasi keragaan teknis khusnya pada kapal purse seine. Rasio dimensi utama yang dimaksud adalah perbandingan L/B, L/D, B/D dimana semakin kecil L/B maka akan berpengaruh buruk terhadap kecepatan kapal karena nilai tahana geraknya akan semakin besar, jika nilai L/D yang semakin membesar akan berdampak pada melemahnya kekuatan memanjang kapal dan nilai B/D yang semakin besar akan memberikan stabilitas kapal yang baik namun propulsive ability-nya akan memburuk. Nilai rasio dimensi utama kapal purse seine sampel akan dibandingkan dengan nilai acuan yang di buat oleh Ayodhyoa (1972), Iskandar dan Pujiati (1995) yang dapat di lihat pada tabel 2 .

Dilihat pada tabel diatas menunjukan bahwa kapal purse seine sampel memiliki nilai L/B sebesar 5.00 menunjukan bahwa kapal purse seine sampel di Kabupaten Pinrang masih berada dikisaran acuan yang ditetapkan oleh Iskandar dan pujiati (1995), sedangkan perbandingan dengan yang dikatakan Ayodhyoa (1972), agak lebih besar namun tidak jauh dari kisaran yang di tetapkan

Tabel 2 Rasio dimensi utama

\begin{tabular}{|l|c|c|c|}
\hline $\begin{array}{l}\text { Rasio dimensi } \\
\text { utama }\end{array}$ & $\begin{array}{c}\text { Nilai Acuan } \\
\text { (Ayodhyoa 1972) }\end{array}$ & $\begin{array}{c}\text { Nilai Acuan } \\
\text { (Iskandar dan } \\
\text { pujiati 1995) }\end{array}$ & $\begin{array}{c}\text { Kapal purse seine } \\
\text { sampel di } \\
\text { Kabupaten Pinrang }\end{array}$ \\
\hline L/B & $4.30-4.50$ & $2.60-9.30$ & 5.00 \\
\hline L/D & $10.00-11.00$ & $4.55-17.45$ & 15.30 \\
\hline B/D & $2.10-2.15$ & $0.56-5.00$ & 3.07 \\
\hline
\end{tabular}


sehingga tidak berpengaruh besar terhadap tahanan yang mempengaruhi kecepatan kapal namun kurang dalam berlolah gerak.

Nilai L/D yang diperoleh dari kapal sampel sebesar 15.30 yang menunjukan bahwa kapal sampel yang berada di Kabupeten Pinrang masih berada dikisaran acuan yang di tetapkan oleh Iskandar dan Pujiati (1995), yang tidak mempengaruhi kekuatan memanjang dan dalam kapal sehingga sudah cukup baik sebagai kapal encircling, namun dalam angka yang di tetapkan Ayodhyoa (1972), kapal sampel yang berada di kabupaten Pinrang memiliki nilai tinggi dengan selisi 4.30, hal ini dapat mempengaruhi kekuatan memanjang kapal sehinnga dapat mempengaruhi manuver kapal dan ketahanan kapal terhadap gelombang.

Nilai B/D yang didapat dari kapal Purse seine sampel sebesar 3.07 yang menujukan bahwa kestabilan kapal purse seine sampel sudah relative baik hal ini di tunjukan dari nilai kisaran yang di acuh dalam Iskandar dan pujiati (1995). Namun dari nilai yang di acuh dari Ayodhyoa (1972), kapal purse seine sampel melebihi dari acuan hal itu berdampak pada bentuk kapal yang ceper namun stabilitas akan tetapi ruangan didalam kapal, palka sangat kecil sehingga banyak muatan yang harus disimpan di atas dek dan jika itu terjadi akan berpegaruh kepada titik berat dan stabilitas kapal.oleh karena itu perlunya penambahan dalam kapal jika mengarapakan banyaknya penyimpanan di bawah dek dan jika tidak maka haruslah mengurangi muatan diatas dek agar tidak mempengaruhi stabilitas dari kapal itu sendiri.

\section{Lines Plan}

Lines plan atau rencana garis merupakan salah satu dasar yang harus ada pada metode pembuatan kapal modern ataupun trandisional. Lines plan merupakan fungsi utama sebagai pedoman dalam pembagunan kapal dalam hal itu body kapal seperti bentuk lurus melengkung tinggi body kapal dimana rencana garis (Lines Plan) di bagi menjadi 3 (tiga) bagian yaitu gambar kapal tampak samping (profile plan), gambar kapal tampak atas (half breadth plan), dan badan kapal tampak depan (body plan). Berdasarkan gambar body plan kapal purse seine KM. Cahaya arafah menujukkan bentuk kasko pada midship berbentuk round bottom dimana bentuk tersebut dapat mempermudah maneuver dan dapat meningkatkan kecepatan kapal yang di sebabkan karenan minimnya tahanan gerak pada kapal sedangkan pada haluan berbentuk $\mathrm{V}$ sehingga memudahkan kapal dalam membelah ombak, bentuk kasko diacuh dalam penelitian Rouf dan Novita (2006), menyatakan bahwa ada lima model kasko kapal-kapal ikan di Indonesia yaitu round bottom, flat bottom, U-bottom, akatsuki bottom dan hard chin bottom.
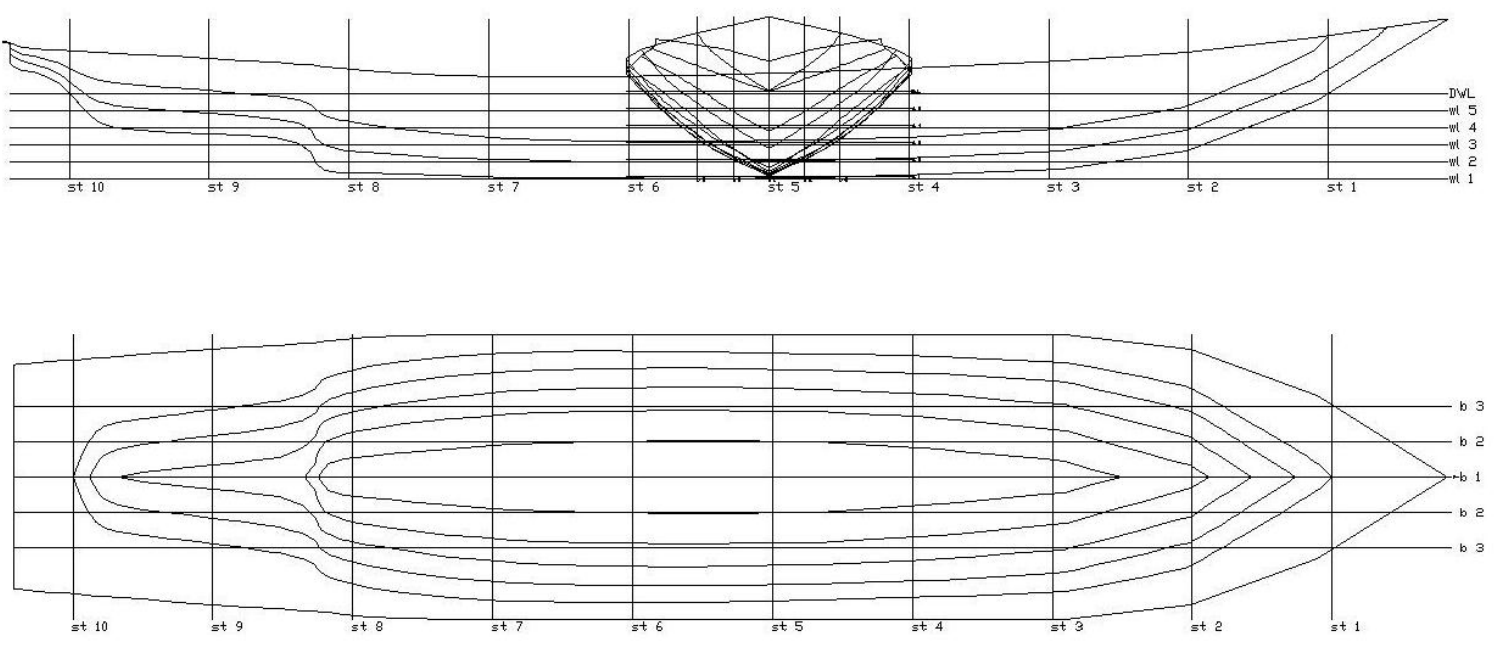

Gambar 2 Lines plan 


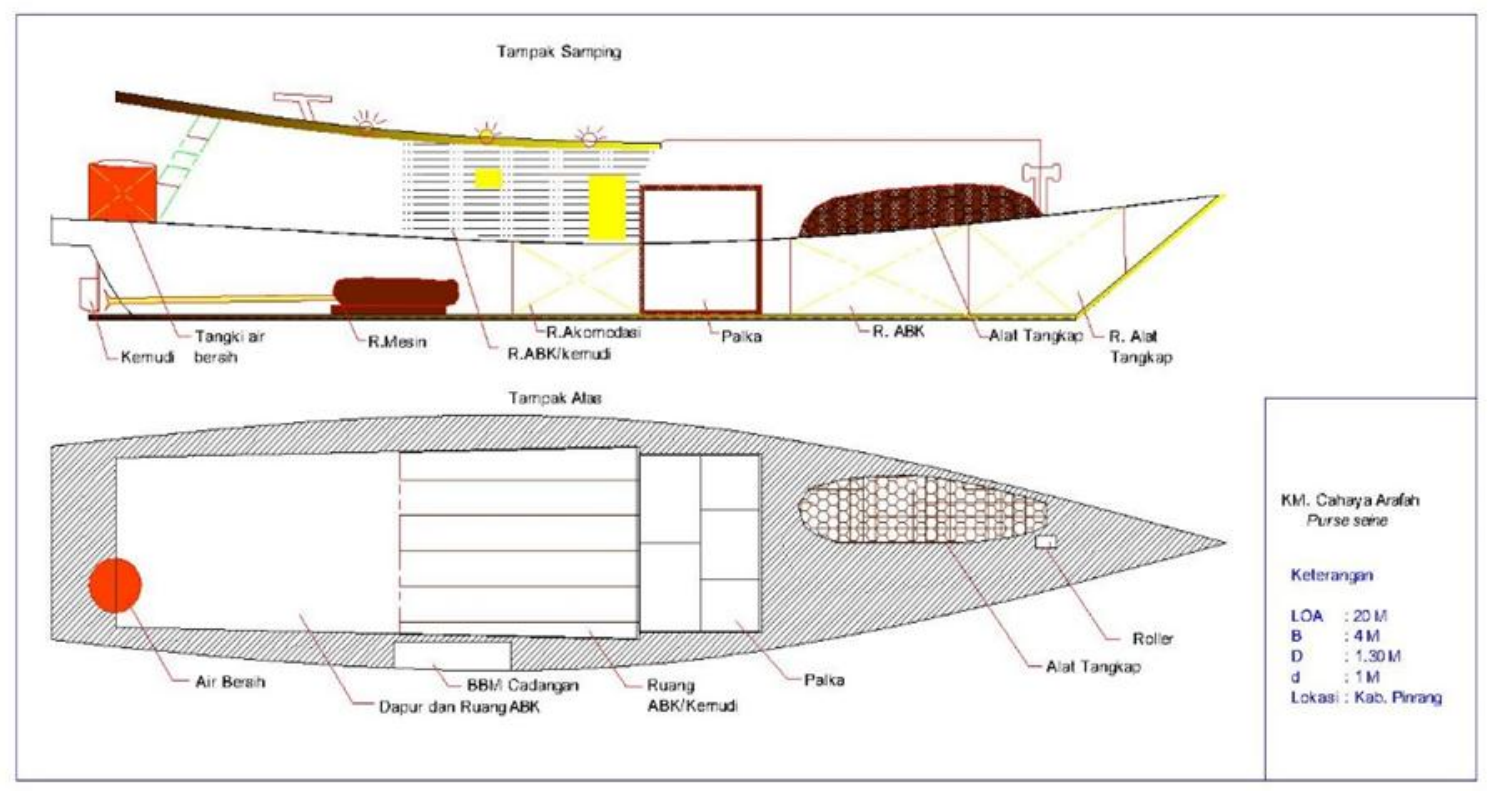

Gambar 3 General arrangement

Lines plan kapal purse seine sampel di Kabupaten Pinrang dapat di lihat pada Gambar 2.

\section{General Araangement}

Rancangan umum (general arrangement) merupakan gambar yang menujukkan tata letak muat diatas kapal. Hal ini sangat penting dalam menunjang kestabilitas kapal seperti tata letak ruangan pada kapal dan muatan kapal. Penempatan ruangan yang baik akan memberikan keleluasaan pada nelayan untuk bekerja diatas kapal hal ini juga berpengaruh kepada stabilitas dan keselamatan kerja diatas kapal. Kapal purse seine di Kabupaten Pinrang dilihat pada Gambar 3. memiliki beberapa ruangan, namun kebiasaan nelayan yang menyimpan alat tangkap diatas dek hal tersebut dilakukan untuk mempermudah saat operasi penangkapan ikan, beberapa ruangan khusus nelayan yang dibuat dibawah dek juga jarang digunakan akantetapi nelayan lebih menyukai berkumpul diruang kemudi, atas ruang kemudi, atas dek haluan kapal dan atas dek pada buritan kapal, pada kapal tersebut dapat dilihat pembagian ruangan sudah baik mulai dari ruang akomodasi dan perbekalan, ruang gudang alat tangkap, ruang mesin, palka ikan, penyimpanan BBM dan air bersih. Gambar rancangan umum kapal purse seine sampel di
Kabupaten Pinrang dapat di lihat pada Gambar 3.

\section{Parameter Hidrostatis}

Parameter hidrostatis merupakan nilai untuk melihat keragaan kapal di mana nilainilai yang menggambarkan kondisi kapal di dalam air pada kondisi air tenang (statis). Karasteritik kapal purse seine di kabupaten pinrang juga akan dilihat pada parameter hidrostatis pada ketinggian air tertentu. Paremeter hidrostatis kapal purse seine di Kabupaten Pinrang dapat di lihat pada Tabel 3.

Dari tabel diatas diketahui nilai volume displacement yang menunjukkan kapasitas atau volume badan kapal yang terendam air pada garis air tertentu, sedangkan berat badan kapal yang terendam air ditunjukkan oleh nilai ton displacement, nilai ton displacement diperoleh dari pengalian dengan masa jenis air laut sehingga didapat nilai displacement dan volume pada KM. Cahaya arafah masingmasing adalah 17,146 ton dan 16,728 $\mathrm{m}^{\wedge} 3$. Parameter TPc menunjukkan jumlah berat yang dibutuhkan untuk mengubah draft kapal purse seine sebesar $1 \mathrm{~cm}$ yaitu sebesar 0,386 ton.

Beberapa parameter hidrostatis yang memiliki pola sama dengan ton displacement dan volume displacement yaitu waterplan area. Waterplant area menunjukan luas badan kapal 
Tabel 3 Parameter hidrostatis KM. Cahaya Arafah

\begin{tabular}{|c|c|c|c|c|}
\hline \multirow{2}{*}{ Measurement } & \multicolumn{3}{|c|}{ Value } & \multirow{2}{*}{ Units } \\
\hline & W1 1 & WL 2 & WL 3 & \\
\hline Displacement & 1,17 & 7,119 & 17,146 & tonne \\
\hline Volume & 1,141 & 6,945 & 16,728 & $\mathrm{~m}^{\wedge} 3$ \\
\hline Draft to Baseline & 0,2 & 0,5 & 08 & $\mathrm{~m}$ \\
\hline Immersed depth & 0,2 & 0,5 & 0,8 & $\mathrm{~m}$ \\
\hline Lwl & 16,385 & 16,989 & 17,538 & $\mathrm{~m}$ \\
\hline Beam wl & 1,041 & 2,314 & 3,063 & $\mathrm{~m}$ \\
\hline WSA & 13,256 & 32,101 & 47,611 & $\mathrm{~m}^{\wedge} 2$ \\
\hline Max cross sect area & 0,106 & 0,621 & 1,435 & $\mathrm{~m}^{\wedge} 2$ \\
\hline Waterplane area & 11,344 & 26,775 & 37,689 & $\mathrm{~m}^{\wedge} 2$ \\
\hline $\mathrm{Cp}$ & 0,658 & 0,659 & 0,665 & \\
\hline $\mathrm{Cb}$ & 0,335 & 0,353 & 0,389 & \\
\hline $\mathrm{Cm}$ & 0,508 & 0,536 & 0,587 & \\
\hline Cwp & 0,665 & 0,681 & 0,702 & \\
\hline LCB from zero $\mathrm{pt}$ & 8,709 & 8,654 & 8,604 & $\mathrm{~m}$ \\
\hline LCF from zero pt & 8,695 & 8,616 & 8.563 & $\mathrm{~m}$ \\
\hline $\mathrm{KB}$ & 0,133 & 0,331 & 0,522 & $\mathrm{~m}$ \\
\hline KG & 0 & 0 & 0 & $\mathrm{~m}$ \\
\hline $\mathrm{BMt}$ & 0,563 & 1,146 & 1,233 & $\mathrm{~m}$ \\
\hline $\mathrm{BMl}$ & 148,152 & 60,758 & 38,217 & $\mathrm{~m}$ \\
\hline GMt & 0,696 & 1,477 & 1,756 & $\mathrm{~m}$ \\
\hline GMl & 148,285 & 61,089 & 38,74 & $\mathrm{~m}$ \\
\hline $\mathrm{KMt}$ & 0,696 & 1,477 & 1,756 & $\mathrm{~m}$ \\
\hline $\mathrm{KMl}$ & 148,285 & 61,089 & 38,74 & $\mathrm{~m}$ \\
\hline Immersion (TPc) & 0,116 & 0,274 & 0,386 & tonne/cm \\
\hline MTc & 0,1 & 0,251 & 0,384 & tonne.m \\
\hline $\mathrm{RM}$ at $1 \mathrm{deg}=$ GMt.Disp.sin(1) & 0,014 & 0,184 & 0,525 & tonne.m \\
\hline
\end{tabular}

yang terendam air (area basah) dan luas penanampang pada tiap garis air secara melintang dari haluan dan buritan luas area basah pada KM. Cahaya arafah 37,689 m^3 yang akan terjadi pada kondisi sarat air maksimum.

LCF (longitudinal center floatation) merupakan jarak titik pusat pengapungan kapal yang dihitung dari tengah kapal (midship) sedangkan LCB (longitudinan center buoyancy) merupakan jarak titik apung kapal secara longitudinal dihitung dari tengah kapal (midship). LCF dan LCB sangat dipengaruhi oleh bentuk lambung kapal yang terendam air. Nilai LCB KM. Cahaya arafah sebesar 8,604 m yang berada didepan midship, sedangkan nilai LCF sebesar $8.563 \mathrm{~m}$ yang berada di belakang midship.
Titik penting yang berpengaruh terhadap keragaan kapal adalah jarak vertical dari lunas kapal (K) ke pusat titik berat $(\mathrm{G})$ dan apung (B). jarak dari lunas kapal ke pusat titik apung disebut dengan KB dan jarak dari lunas kapal ke titik berat disebut dengan KG. nilai KG akan bertambah dengan pertambahan draft dan KG semakin berkurang dengan dalamnya kapal yang terendam air. Nilai KG KM. Cahaya arafah sebesar $0 \mathrm{~m}$ dan nilai KB 0,522 m. hal ini berati titik berat kapal berada lebih rendah dari titik apungnya.

Titik metacenter dibagi menjadi dua yaitu $\mathrm{M}_{\mathrm{t}}$ dan $\mathrm{M}_{\mathrm{L}}$. Jarak titik apung terhadap metacenter secara vertical atau $\mathrm{BM}_{\mathrm{t}}$ adalah 1,233 m dan jarak lunas terhadap metacenter $\left(\mathrm{KM}_{\mathrm{t}}\right)$ adalah 1,756 m sementara jarak dari titik berat terhadap metacenter $\left(\mathrm{GM}_{\mathrm{t}}\right)$ adalah 1,756 m. hal ini menjujukkan bahwa kapal KM. 
Tabel 4 Perbandingan Nilai koefisien kapal purse seine KM. Cahaya Arafah

\begin{tabular}{c|c|c|c|}
\hline $\begin{array}{c}\text { Koefisien } \\
\text { bentuk }\end{array}$ & $\begin{array}{c}\text { Kapal purse seine } \\
\text { Pinrang (KM.Cahaya } \\
\text { arafah) }\end{array}$ & $\begin{array}{c}\text { Kapal purse seine } \\
\text { Indonesia (Iskandar dan } \\
\text { Pujiati 1995) }\end{array}$ & $\begin{array}{c}\text { Kapal purse seine } \\
\text { Jepang (Ayodhyoa }\end{array}$ \\
\hline $\mathrm{Cb}$ & 0.389 & $0.56-0.67$ & $1972)$ \\
\hline $\mathrm{Cp}$ & 0.665 & $0.60-0.79$ & $0.57-0.68$ \\
$\mathrm{Cm}$ & 0.587 & $0.84-0.96$ & $0.67-0.75$ \\
\hline $\mathrm{Cw}$ & 0.702 & $0.78-0.88$ & $0.91-0.95$ \\
\hline
\end{tabular}

Cahaya arafah berada diatas titik G sehingga kapal memiliki kestabilan yang positif. Metacenter membujur $\left(\mathrm{M}_{\mathrm{L}}\right)$ merupakan titik perpotongan antara garis-garis tegak yang memalui titik B secara membujur. Hal ini menggabarkan mengenai kondisi draft dimana nilai yang didapatkan yaitu $\mathrm{BM}_{\mathrm{L}} 38,217 \mathrm{~m}$, GML 38,74 m, KML 38,74 m.

Koefisien bentuk kapal merupakan nilai-nilai koefisien dari parameter hidrostatis yang dapat menggambarkan bentuk kapal dapat di ketahui kemampuan dan karasteristik sebuah kapal. Nilai koefisien yang dimaksud adalah coefficient block (Cb), prismatic coefficient (Cp), koefisien midship (Cm), waterplan coeffisien, dan vertical prismatic coefficient (Cvp). Kapal purse seine di Kabupaten Pinrang KM. Cahaya arafah memiliki nilai kefisien bentuk $\mathrm{Cb}$ dan $\mathrm{Cp} 0.389$ dan 0,665yang menujukkan bentuk yang tergolong ramping. Nilai $\mathrm{Cb}$ kapal purse seine menujukkan belum berada pada nilai rentang kapal-kapal purse seine di Indonesia dan jepang, namun nilai $\mathrm{Cp}$ sudah memenuhi rentang nilai kapal-kapal purse seine di Indonesia dan di Jepang, nilai Cm yang di peroleh kapal purse seine di Kabupaten Pinrang KM. Cahaya arafah adalah 0.587 tidak mencapai rentang $\mathrm{Cm}$ kapal purse seine di Indonesia dan kapal purse seine di Jepang hal ini menujukkan bahwa pada bagian midship kapal purse seine di Kabupaten Pinrang memiliki bentuk yang ramping. Nilai $\mathrm{Cp}$ dan $\mathrm{Cm}$ yang besar menunjukkan meningkatkan ke stabilitas kapal namun mengurangi kecepatan kapal akibat tahan kapal (Nurdin 2014), begitu pula yang dikatakan oleh Susanto et al 2011, bahwa nilai $\mathrm{Cp}$ dapat digunakan untuk mengetahui besarnya tahanan gerak kapal, yaitu semakin besar nilai Cp maka semakin besar pula nilai tahan gerak yang dimiliki oleh sebuah kapal. Perbandingan nilai dari kapal purse seine di Kabupaten Pinrang KM. Cahaya arafah dapat dilihat pada Tabel 4.

\section{Kesimpulan}

Kesimpulan dari penelitian ini adalah:

1. Nilai ratio dimensi utama kapal purse seine di Kabupaten Pinrang KM. Cahaya Arafah sudah sesuai dengan nilai kapalkapal purse seine (encircling) di Indonesia namun belum menyamai dengan kapal purse seine di Jepang yang memiliki bentuk body tidak panjang namun dari segi stabilitas tinggi dikarenakan standar kapal di Jepang merupakan kapal-kapal dengan pembangunan secara modern sedangkan kapal di Indonesia masih banyak membagun secara tradisional.

2. Kapal purse seine di Kabupaten Pinrang memiliki model kasko yang berbentuk round bottom dan jumlah berat yang dibutuhkan untuk mengubah draft kapal purse seine sebesar $1 \mathrm{~cm}$ yaitu sebesar 0,386 ton. Nilai koefisien bentuk hanya Cp yang berada pada kisaran sehingga sesuai dengan tahanan gerak pada kapal encircling namun kapal ini memiliki bentuk body yang ramping dilihat dari nilai $\mathrm{Cb}$ dan $\mathrm{Cm}$ akantetapi stabilitas kapal ini baik dilihat dari nilai $\mathrm{Cw}$ yang sudah sesuai dengan nilai kapal encircling di Indonesia. 


\section{DAFTAR PUSTAKA}

Ayodhyoa AU. 1972. Suatu Pengenalan Kapal Ikan. Bogor (ID): Fakultas Perikanan, Institut Pertanian Bogor.

Farhum St.A. 2010. Kajian Stabilitas Empat Tipe Kasko Kapal Pole and Line. Jurnal Ilmu dan Teknologi Kelautan Tropis. 2(2): 53-61.

Fyson J. 1985. Design of Small Fishing Vessels. Farnham-Surrey (GB): Fishing News Book Ltd.

Iskandar BH, S Pujiati. 1995. Keragaan Teknis Kapal Perikanan di Beberapa Wilayah Indonesia (Laporan Penelitian). Bogor (ID): Jurusan Pemanfaatan Sumbardaya Perikanan, Fakultas Perikanan, Institut Pertanian Bogor.

Nurdin HS. 2014. Stabilitas Kapal Purse Seine Modifikasi di Kabupaten Bulukumba Sulawesi Selatan [Tesis]. Bogor (ID): Institut Pertanian Bogor.

Palembang S, Luasunaung A, Pangalila FPT. 2013. Kajian Rancang Bangun Kapal Ikan Fibreglass Multifungsi 13 GT di Galangan Kapal CV Cipta Bahari Nusantara Minahasa Sulawesi Utara. Jurnal Ilmu dan Teknologi Perikanan Tangkap. 1(3): 87-92.

Rouf ARA dan Novita Y. 2006. Studi Tentang Bentuk Kasko Kapal Ikan di Beberapa Daerah di Indonesia. Jurnal Torani. 16(4): 51-62.

Susanto A, Iskandar BH, Imron M. 2010. Stabilitas Statis Kapal Static Gear di Palabuhanratu (Studi Kasus KM. PSP 01). Marine Fisheries. 2(1): 65-73. 